\title{
Role of Augmented Reality Applications for Smart City Planning
}

\author{
Jha Suchita, Joshi Sujata
}

\begin{abstract}
India is on the cusp of technology transformation resulting in adoption of technology. . In this context when we look into the technological advancements, there are various technological tools which are affecting us and one of them is Augmented Reality (AR). Especially in the context of smart city initiative of the Indian Government, upcoming technologies like $A R$ play a vital role for development of the smart city infrastructure. Hence the objective of this study is to conceptualize a model for smart city infrastructure from perspective of 4 pillars of smart city planning viz: Mobility, Connectivity, Security and Sustainability. The paper adopts a narrative literature review based approach in order to arrive at a conceptual model on the basis of evaluation, and analysis of literature on the topic under investigation in this study. This study has implications for the academicians, practitioners and society at large as it adds to the academic literature on use technology in smart city infrastructure building and the urban planners and government officials can use this technology to improve city services, infrastructure, environment and quality of life of the citizens.
\end{abstract}

Keywords - Augmented Reality, Smart city Planning, Smart Infrastructure, Sustainability, Connectivity, Mobility, Security.

\section{INTRODUCTION}

India is on the cusp of technology transformation resulting in adoption of technology not only in business but also in other facets of our personal life. In this context when we look into the technological advancements, there are various technological tools which are affecting us and one of them is Augmented Reality (AR). AR has the capability of bringing about a change in the consumer behavior, and the business process management. Augmented Reality is more visual, contextual and visceral in nature hence it helps in creating interactive experience with the world around us. The aim of AR tools is to enhance the various objects around us by augmenting them capabilities of communication digitized information.

In the Indian context, the postulation of "Smart Cities" holds great importance as it strives to elevate the standard of living of the inhabitants by improving the management of infrastructure, governance, water, power, water, health, education, safety-security etc. India is amongst the rapidly

Revised Version Manuscript Received on July 18, 2019.

Jha Suchita, Assistant Professor, Symbiosis Institute of International Business, constituent of Symbiosis International (Deemed University), Hinjewadi, Pune, India. (Email: suchita.jha@siib.ac.in)

Joshi Sujata, Professor, Symbiosis Institute of Telecom Management, constituent of Symbiosis International (Deemed University), Lavale, Pune, India.( Email: sjoshi@sitm.ac.in) developing countries globally wherein by the year 2030 the urban cities are expected to dwell a population of around $40 \%$

(India.gov.in) [1] hence infrastructure development is a prime concern in India. This requires a major change in the infrastructure of urban areas which has been promoted through the smart city initiative by the Indian Government. The Indian cities are facing challenges of growing population, infrastructure and pollution, and smart city initiative comes out as a way to resolve these problems with the help of technology and innovation. (Euro monitor International 2018) [2]. For developing the smart city infrastructure, new and upcoming technologies like Augmented Reality (AR) can play a very vital role. In a country where cities are not planned and developed haphazardly it is important to have a tool to interact with all stakeholders and know their major concerns. Thus Augmented Reality comes as a solution to resolve the concern of all involved with smart city infrastructure.

Smart city in context of India is comprehensive development in the area of institutional, physical, social and economic infrastructure. Presently this industry is also having lot of growth which creates huge potential for business. As per the Smart Cities Association [3], Smart city industry is currently a $\$ 900$ billion industry globally and forecasted to be nearly $\$ 3.5$ trillion by 2026 . Augmented reality can be applicable on six major areas of infrastructure development that is governance, assets management, public safety, public health, transportation and culture/heritage of the place.

In the field of e governance augmented reality application can be used in the area of policy framework. Legal and regulatory documents can be transferred truly into "living" form of documents with the ability to interact with the native people and the officers through augmented reality devices. City assets like streetlights, cell towers and fire towers can be managed and maintained via augmented reality applications. Augmented Reality devices can help during disaster and emergency situations by providing assistance through audio and visual forms for obtaining shelter, finding evacuation paths, or seeking exigency assistance. AR applications can be applicable in the areas like sustainability and public health wherein augmented reality devices can help in detecting environmental quality and enable the concerned officers and the native people of that region to take quick decisions. Augmented reality can help in transport 
management, urban mobility and road accident issues and through this time and life can be saved. Augmented Reality thus helps in education

people to preserve the natural resources, cultural and social heritage of a place.

As we can see augmented reality applications can provide several benefits especially from smart city perspective in an Indian context. Hence this study takes a looks at the benefits of augmented reality applications for smart city infrastructure and aims to conceptualize a model from perspective of 4 pillars of smart city planning viz: Mobility, Connectivity, Security and Sustainability.

\section{LITERATURE REVIEW}

Several studies have been conducted in the area of augmented reality wherein the focus has been on application of augmented reality in different verticals such as public transport, shopping, education, gaming, navigation, museums, tourism, rehabilitation, marketing, smart parking, interior design etc.

Augmented reality (AR) and its application in smart city infrastructure have been studied with specific reference to public transport system ( Pokric, B., et al 2014) [4]. AR applications have been used for shopping function especially for motor disabled and physically challenged individuals. (Rashid, .et al 2017) [5]. Ozcan, U et al (2017) [6] investigated the application of augmented reality within college campus in which they developed an AR prototype for visual aid within campus. B.Pokric, et al. (2015) [7] conducted a study on use of IOT services using AR technology for providing environmental data. Karl Rehrl et al (2014) [8] worked on Pedestrian navigation with augmented reality. Francesca Bertacchini et al (2012) [9], in their study have investigated the use of AR in museums, Osamah.; R. et al (2014) [10] have studied the use of augmented reality application for tourism. Díaz H.et al (2017) [11] in their research on augmented reality propose an offline mobile-application for place identification using augmented reality. Roberto Pierdicca et al (2016)[12] in their study discuss the use of AR for enhancing experiences using mobile devices. Garcia-Crespo et al (2018)[13] presented a structure for designing a cultural entertainment system using Brum., et al (2015) [14] conducted a study on Virtual Reality and Internet of Things applications specific to smart cities for accentuating solutions for health and rehabilitation. Bovcon, $\underline{\mathrm{N}}$., et al (2013) [15] has presented the use of augmented reality application for the purpose of art. Bellini, A., et al (2013) [16] has studied the application of augmented reality on city heritage and virtual museum. Lin, C.-M., et al (2018) [17] talked about the application AR in increasing community interaction and marketing in the village. Al-Jabi, \& Sammaneh, H. (2018) [18] gave the insight on usage of AR in parking management. Ramos, F., ET al (2018) [19] illustrate the prospects of using AR tools for creating a smart campus. . Sharma, S. et al (2018) [20] proposed a novel method for application of AR technology in interior design wherein the users can get a $3 \mathrm{D}$ virtual view of the furniture and also communicate with the vendor using a robust user interface. Demir \& Karaarslan (2018)[21] have used the AR technology for developing a prototype of mobile application to be used for smart tourism.

\section{OBJECTICVE OF PAPER}

The smart city initiative of the Indian Government shows that they are very keen on the application of technology for better experience to citizens so it is utmost important concern to study the AR application for smart city within India. The cited literature shows that significant work has been done in the field of augmented reality and its application in smart city. However, the review of various studies shows very few studies have been conducted in academic literature from perspective of the 4 pillars of smart city planning viz : Mobility, Connectivity, Security and Sustainability as proposed by Smart Regions Initiative (June 2017) [22]. Hence the objective of the study is to conceptualize a model for smart city infrastructure from perspective of 4 pillars of smart city planning viz: Mobility, Connectivity, Security and Sustainability.

\section{RESEARCH METHOD}

The study has been done taking into consideration various peer reviewed literature in the area of augmented reality, smart city planning, and smart infrastructure. Most relevant research papers and articles were generated through the keywords of 'Augmented reality', 'Smart city planning', 'Smart infrastructure', 'AR and mobility, 'Augmented reality and Connectivity', 'Augmented reality and security', 'Augmented reality and Sustainability'. Papers were retrieved from online databases such as Scopus, Ebsco, Google scholar etc. Since the topic in consideration is an upcoming technology area, the data for this study has been collected through various online databases, whitepapers, articles and reports as well. Collected literature was then analyzed for relevance from perspective of the 4 pillars of smart city planning as stated above.

As defined by Fink (2014)[23], “A literature review surveys books, scholarly articles, and any other sources relevant to a particular issue, area of research, or theory, and by so doing, provides a description, summary, and critical evaluation of these works in relation to the research problem being investigated. Literature reviews are designed to provide an overview of sources you have explored while researching a particular topic and to demonstrate to your readers how your research fits within a larger field of study". According to Carnwell and Daly (2001) [24], a thorough review of literature would mean collecting information about the topic under consideration from several resources. The researcher must have a clear cut strategy regarding tee arch and selection of information.

As per Cronin et al (2008) [25], a narrative or traditional

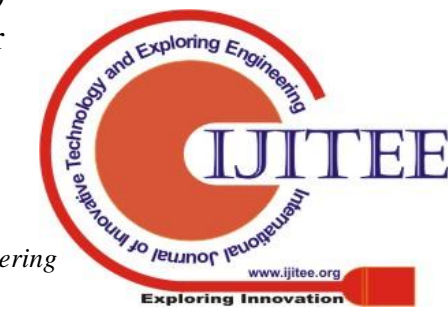


type of literature review consists of several studies which contain knowledge pertaining to the topic under investigation. This study is very selective in nature as it considers studies relevant to the topic, which sometimes may not be outright apparent to the readers. This method is especially relevant when the researcher wishes to summarize and synthesize lot of information pertaining to a specific topic. Such a method is also useful when the researcher wants to refine, select a broad research question with an aim of creating a conceptual model or framework. (Beecroft et al, 2006) [26].

\section{CONCEPTUAL MODEL AND RESEARCH QUESTIONS:}

The Institute of Electrical and Electronics Engineers (IEEE) envisions a smart city as "one that brings together technology, government, and society to enable the following characteristics: a smart economy, smart mobility, a smart environment, smart people, smart living, and smart governance." Sachsenmeier, R. et al (2015) [27]. As per the Smart Regions Initiative (2017), Connectivity, Mobility, Security and Sustainability are considered as the four major pillars which can determine the success of smart city planning.

In this section we try to discuss the role of the upcoming technology, Augmented Reality in smart city infrastructure from perspective of 4 pillars of smart city planning viz: Mobility, Connectivity, Security and Sustainability. The study wishes to address the following research questions trough literature review:

1) Do augmented reality applications play a significant role on the 4 pillars of smart city planning viz mobility, connectivity, security and sustainability?

2) Can augmented reality applications be useful for mobility in smart city infrastructure planning?

3) Can augmented reality applications be useful for connectivity in smart city infrastructure planning?

4) Can augmented reality applications be useful for security in smart city infrastructure planning?

5) Can augmented reality applications be useful for sustainability in smart city infrastructure planning?

Based on literature review and the above research questions following conceptual model is proposed for AR application and its Benefits for smart city infrastructure: (Based on 4 pillars of smart cities).

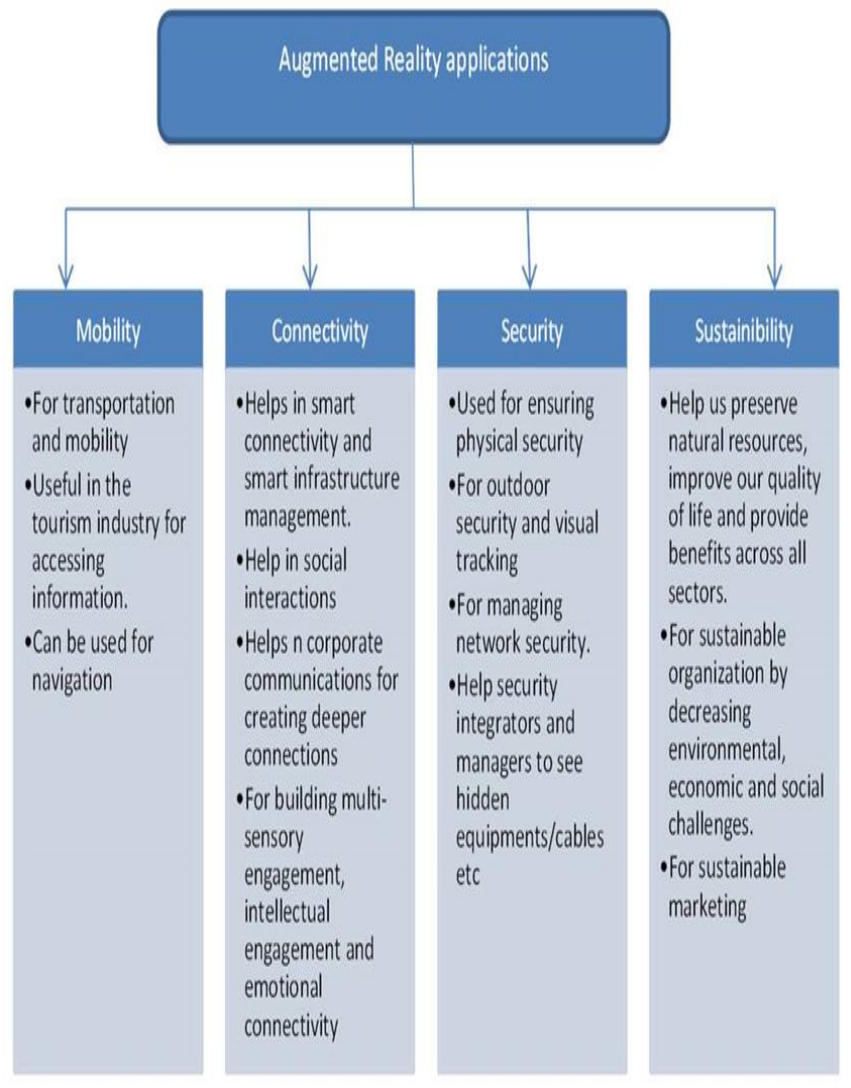

Fig 1: Conceptual model for AR application and its Benefits for smart city infrastructure: (Based on 4 pillars of smart cities)

\section{RESULTS, ANALYSIS AND DISCUSSIONS}

6.1 AR applications and Mobility:

Mobility discussed here is not just from perspective of movement from one place to another but also about provision of facilities which aid mobility like education access, job training, career advancement, business growth etc. Augmented reality applications can be used for transportation and mobility wherein fixes transportation infrastructure like road, rail, highways etc. can be visually connected through AR applications which will provide real time information regarding schedules, accidents, routes etc. and also help in navigation.

Kounavis et al (2012) [28] in their study have discussed how mobility can be enhanced with the help of augmented reality in tourism industry. AR applications prove to be useful in the tourism industry by helping tourists to access information regarding tourist destinations, enhancing tourist experience etc. Pokric et al. (2014) [4] conducted a research with the purpose of seeing augmented reality's application in smart city infrastructure specifically to public transport system of Novi Sad in Serbia, such as bus arrival time, bus routes and tourist landmarks using smart phones and AR 
technology and they found that AR streamlines the studied factors positively. Curtin, G., (2019) [29], in his report in CIO

Review, talks about the application of augmented reality on mobility in smart city. In Urban mobility individuals can get information on individual mobility, car or bike pool. He talks about how AR applications can be used for navigation, real time information about routes, get traffic information, safety and efficiency of public transport vehicles. In short he focusses on how augmented reality applications can be used to make urban mobility more accessible and safer.

Proposition 1: Augmented reality applications can be useful for mobility in smart city infrastructure planning

\subsection{AR applications and Connectivity:}

Connectivity is the basic foundation of smart city planning. All technologies required for smart cities rely on the transmission of data in real time which is possible though efficient connectivity. Connectivity not only helps in transmission but also connects the rural population to the urban areas and helps in the creation of opportunities. Technologies like IoT require $\mathrm{AR}$ in order to make the real-time visualization of data especially when it comes to the visualization of contextual information or showing live data on machines, cars or any other objects. The high value experts can be connected via AR applications (Audio, visual, sensory etc.) to provide technical guidance to the field workers. Thus AR helps in smart connectivity and smart infrastructure management.

Tison et al (2012) [30] worked on their paper on port connectivity. They emphasize the use of augmented reality on increasing connectivity. Kounavis et al (2012) [28] discussed how application of augmented reality eases the connectivity between people to increase tourism. The paper expresses that by using AR applications tourists can connect with each other to exchange information, tips, and experiences. AR applications can be considered as social applications as they help in social interactions. Alton (2017) [31], discusses the role of AR in corporate communications and how it can be used for creating deeper connections and adding interactivity to data visualization. As per this article AR can be used by brands to evoke stronger emotions, to develop interactive simulations for customers and create in person experiences. Augmented Reality can be used in the ecommerce sector for building multi- sensory engagement, intellectual engagement and emotional connectivity. (Finn, G. 2017) [32].

Proposition 2: Augmented reality applications can be useful for connectivity in smart city infrastructure planning.

\section{3: AR applications and Security:}

As the infrastructure in smart cities is based on technologies hence both physical as well as cybersecurity assumes great importance. As per the article by Forte (2016) [33] Augmented reality applications can be used for ensuring physical security since these applications can Project and interact with any information, anywhere allowing security directors to access information and manage a crisis from anywhere. The $\mathrm{x}$ ray vision and gaze tracking capabilities of AR applications can help security integrators and managers to see equipment/cables etc. hidden behind walls or under the floors etc. The AR applications can help capture real-time information from devices.

Apvrille, (2018) [34] worked on use of augmented reality for managing network security. The network object is identified from the reality image by the augmented reality device. A virtual image is generated by use of augmented reality. The augmented overlay image is displayed by the augmented reality device. Zhu, W., et al. (2004) [35] worked on e-store security with the use of augmented reality. In this paper they have worked on an e-commerce store system which helps in providing assistance in shopping and also helped in personalized advertising with the use of augmented reality, which helped in increasing the overall consumer experience. Kameda, Y., et al (2004) [36] worked on outdoor security and visual tracking with the help of augmented reality application.

Proposition 3: Augmented reality applications can be useful for security in smart city infrastructure planning.

\section{4: AR applications and Sustainability.}

It is very essential to be conscious of sustainability while implementing smart city solutions as sustainable practices will help us preserve natural resources, improve our quality of life and provide benefits across all sectors be it agriculture, manufacturing, services or any other industry. Augmented reality applications can be used for encouraging healthy and sustainable living for citizens.

AR combined with environmental sensors can help environmental officials and citizens to make real-time decisions on movement, activity etc. (Curtin, G. 2017) [37]. Damiani, L., et al (2018) [38] discussed the application of augmented reality for sustainable development in mining. Mining is a key industry in the global society and global economy .The mining industry needs major upliftment and this paper worked on how augmented reality can reduce waste in mining sector and help in sustainable development. Segovia, D., et al. (2015) [39] have worked on the impact of augmented reality application on sustainable organization where they focused on decreasing environmental, economic and social challenges and thus they want to align their processes and services with a sustainability agenda with the use of augmented reality. Bulearca \& Tamarjan (2010) [40] discussed in their research that augmented reality is also used as a sustainable marketing tool. The cognitive and emotional impact of AR is stronger than similar exposures to traditional TV advertising or web-browsing.

Proposition 4: Augmented reality applications can be useful for sustainability in smart city infrastructure planning.

\section{IMPLICATIONS ANDFUTURE RESEARCH DIRECTIONS}

The study has been conceptualised with the objective of understanding the benefits of Augmented Reality applications for smart city infrastructure from perspective of the 4 pillars of smart city planning viz Mobility, Connectivity, Security and Sustainability. Future

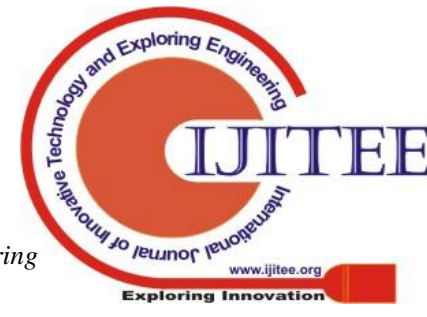


research can be conducted for testing the impact of AR applications on the business of an organization from perspective of the above mentioned 4 pillars of smart city planning.Augmented reality applications are useful in the various sectors for creating Mobility such as in transportation industry for navigation, in the tourism industry for accessing information etc. Similarly, AR applications aid in connectivity as they help in smart connectivity and smart infrastructure management, help in social interactions, in corporate communications for creating deeper connections and for building multi- sensory engagement, intellectual engagement and emotional connectivity. AR applications can be helpful in creating security solutions which can be used for ensuring physical security, for outdoor security and visual tracking, for managing network security and for helping security integrators and managers to see hidden equipment/cables etc. Finally AR applications can be useful in creating sustainability solutions which help us preserve natural resources, improve our quality of life and provide benefits across all sectors, which help in creating sustainable

organization by decreasing environmental, economic and social challenges and which help sustainable marketing.

This study has implications for the academicians as will add to the academic literature on use technology in smart city infrastructure building. It provide implications to practitioners, and society at large as the urban planners and government officials can use this technology to improve city services, infrastructure, environment and quality of life of the citizens. The study can be useful to Government officials, town-planners, architects, builders, for smart city planning. It will prove helpful to infrastructure companies for designing,

creating and providing solutions which will aid in smart city infrastructure management and creating smart cities.

\section{REFERENCES}

1. India.gov.in portal. "Smart Cities Mission. Building a smart India”.

Available at https://www.india.gov.in/spotlight/smart-cities-mission-s tep-towards-smart-india Access on : $24^{\text {th }}$ May, 2019

2. Euro monitor International, "Smart Cities: Empowering the Globe's Urban Ecosystems" (June 2018).

3. Available es-urban-ecosystems/report Accessed on: $27^{\text {th }}$ May, 2019

4. Smart Cities Association. "Global smart cities market to reach a whopping $\$ 3.5$ trillion by $2026 " 2017$ [online].Available athttps://www.smartcitiesassociation.org/index.php/mediaco rner/news/1-global-smart-cities-market-to-reach-a-whopping -3-5-trillion-by-2026 access on : $20^{\text {th }}$ May,2019

5. Pokric, B., Krco, S., \& Pokric, M. "Augmented reality based smart city services using secure IoT infrastructure" (2014). [online] Proceedings - 2014 IEEE 28th International Conference on Advanced Information Networking and Applications Workshops, (pp. 803-808). IEEE WAINA at www.euromonitor.com/smart-cities-empowering-the-glob

2014. Available at https://doi.org/10.1109/WAINA.2014.127Accessed on $19^{\text {th }}$ May, 2019

6. Rashid, Zulqarnain, Seguí., Joan; Melià., Pous Rafael; Peig., Enric. "Using Augmented Reality and Internet of Things to improve accessibility of people with motor disabilities in the context of Smart Cities." (2017). [online] Future Generation Computer Systems 76. Pp-248-261 Available at 10.1016/j.future.2016.11.030. Accessed on : $10^{\text {th }}$ May, 2019

7. Ozcan, U., Arslan, A., Ilkyaz, M., \& Karaarslan, E “An augmented reality application for smart campus urbanization: MSKU campus prototype.” (2017). ICSG 2017 - 5th International Istanbul Smart Grids and Cities Congress and Fair.

Available at https://doi.org/10.1109/SGCF.2017.7947610 Accessed on : $27^{\text {th }}$ May, 2019

8. B.Pokric, S.Krco, D.Drajic, M. Pokric et al. "Augmented Reality enabled IoT services for environmental monitoring utilising serious gaming concept". Journal of Wireless Mobile Networks, Ubiquitous Computing, and Dependable Applications, volume: 6, number: 1, pp. 37-55. (2015).

9. Karl, Rehrl., Elisabeth, Häusler., Sven, Leitinger., Daniel, Bell. "Pedestrian navigation with augmented reality, voice and digital map: final results from an in situ field study assessing performance and user experience." Journal of Location Based Services. Volume 8, Issue 2, Pages: 75-96. (2014).

10. Francesca, Bertacchini., Eleonora, Bilotta., Manuela, Carini., Lorella, Gabriele., Pietro, Pantano., Assunta, Tavernise "Learning in the smart city: A virtual and augmented museum devoted to chaos theory" . (2012).. International Conference on Web-Based Learning. Pages: 261-270.

11. Osamah Rabab'ah, Abrar Omar Alkhamisi, Amin Saif Ahmad "Measure Quality Augmented Reality Tourist Using in Mobile Technology." International Journal of Engineering Research and Development Volume 10, Issue 5 (May 2014), PP.26-40. (2014).

12. Díaz H. Marjury; Barberán C. Karen; Martínez-M. Diana; López F. Gabriel "Offline mobile application for places identification with augmented reality" 2017).. Available at DOI: 10.1109/ICEDEG.2017.7962546. Accessed on $20^{\text {th }}$ May, 2019

13. Roberto Pierdicca, Emanuele Frontoni, Primo Zingaretti, Eva Savina Malinverni, Andrea Galli, Ernesto Marcheggiani, Carlos Smaniotto Costa "Cyber archaeology: improved way findings for archaeological parks through mobile augmented reality" (2016).[online] International Conference on Augmented Reality, Virtual Reality and Computer Graphics. Pages 172-185

14. García-Crespo, Á., González-Carrasco, I., López-Cuadrado, J.L., Villanueva, D., González, Á. "CESARSC: Framework for creating cultural entertainment systems with augmented reality in smart cities." (2016). Computer Science and Information Systems 13(2):395-425 Available at 10.2298/CSIS150620006G Accessed on : 16th May,2019

15. Brum, Manoela Rogofski., Rieder, Rafael. "Virtual reality applications for smart cities in health: A systematic review" .XVII Symposium on Virtual and Augmented Reality. Pages: 154-159. (2015).

16. Bovcon N., Vaupotič A., Klemenc B., Solina F. "Augmented Reality: A Case Study in the Domain of Fine Arts." Lecture Notes in Computer Science, vol 7946. Springer, Berlin, Heidelberg. (2013).

17. Bellini, A. Luddi., C; Naldini.,S; Ghetti.,C., Bellini.,E., and 
Bergamin., "Once Upon a Time: A Proof of Concept Augmented Reality Collaborative Mobile Application to Discover City heritage" .International Conference on Signal-Image Technology \& Internet-Based Systems, pp. 358-363. . (2013). Lin, Cheng-Min \& Lin, Tzu-Chi \& Lin, Yu-Ching \& Wang, Chao-Ming \& Dow, Chyi-Ren. "Community Interaction and Marketing Using 3D Coloring Augmented Reality in Zhongxing New Village" (2018).15th International

18. Symposium on Pervasive Systems. 272-276. Available at 10.1109/I-SPAN.2018.00052.

DOI:10.1109/i-span.2018.00052Accessed on : 20th May, 2019

19. Al-Jabi Muhannad, Sammaneh Haya "Toward Mobile AR-Based Interactive Smart Parking System". IEEE 16th International Conference on Smart City. Pages: 1243-1247., 2018

20. Ramos, F.; Trilles, S.; Torres-Sospedra, J.; Perales, F.J. "New Trends in Using Augmented Reality Apps for Smart City Contexts" (2018). [online]ISPRS Int. J. Geo-Inf. 7(12), 478. Available at https://doi.org/10.3390/ijgi7120478. Accessed on: 18th May,2019

21. Sharma. Santosh; Kaikini. Yash; Bhodia., Parth; Vaidya., Sonali "Markerless Augmented Reality based Interior Designing System" (2018). [online] International Conference on Smart City and Emerging Technology (ICSCET). Pages: 1-5. Available at 10.1109/ICSCET.2018.8537349 Accessed on : 4th May,2019

22. Demir Ömer Faruk, Karaarslan Enis ,"Augmented Reality Application for Smart Tourism" ,6th International Istanbul Smart Grids and Cities Congress and Fair (ICSG)2018..Available at DOI:10.1109/SGCF.2018.8408965 Accessed on : 14th May,2019

23. Smart Regions Initiative "The Pillars of Smart Cities." (June 18, 2018). [online] Available at https://www.smartregions.org/blog/the-four-smart-city-pillar s Accessed on : 29thapril,2019

24. Fink, Arlene. Conducting Research Literature Reviews: From the Internet to Paper. Fourth edition. Thousand Oaks, CA: SAGE, 2014.

25. Carnwell R, Daly W "Strategies for the construction of a critical review of the literature". Nurse Educ Pract 1: 57-63. (2001)

26. Cronin, P., Ryan, F., Coughlan, M., "Undertaking a literature review: a step-by-step approach" British Journal of Nursing, 2008, Vol 17, No 1 (2008).

27. Beecroft $\mathrm{C}$, Rees A, Booth A "Finding the evidence. In: Gerrish K, Lacey A, eds." The Research Process in Nursing. 5th edn. Blackwell Publishing, Philadephia: 90-106. (2006)

28. Sachsenmeier, R. et al "Guide to Open Government chapter 3 - Smart Cities" 2015.[online] Available athttps://www.researchgate.net/profile/Piet_Kommers/publi cation/282219165_Guide_to_European_Open_Government C/links/56084ed608ae5e8e3f3a8a58/Guide-to-European-Op en-Government-C.pdf Accessed on : 7th May,2019

29. Kounavis, C. D., Kasimati, A. E., \& Zamani, E. D. "Enhancing the tourism experience through mobile augmented reality: Challenges and prospects." International Journal of Engineering Business Management, 4, 10. (2012).

30. Curtin, C., "Augmented Reality to Improve Urban Mobility. CIO Review." (2019) [Online] available at https://ar-vr.cioreview.com/cxoinsight/augmented-reality-toimprove-urban-mobility-nid-14344-cid-135.html Accessed on : 30th April,2019

31. Tison, J. D., Smolinski, Z. J., O'donnell, J. P., \& Doorhy, B. F "U.S. Patent Application No. 13/426,065." (2012).
32. Alton, Liz. "How augmented reality can deliver impactfulcommunications"10thOctober, 2017 [Online]. Available at https://blog.investisdigital.com/how-augmented-reality-candeliver-impactful-communications Accessed on : 22nd May, 2019

33. Finn, G. "Why Augmented Reality and Virtual Reality Will be Important for Your Business Entrepreneur" 12th September, 2017 [online] Available at https://www.entrepreneur.com/article/300071. Accessed on : 25th May, 2019

34. Fortem "Augmented Reality for Physical Security" 2016 [Online]. Available at http://fortem.com/augmented-reality-for-physical-security/ Access on : 19th May,2019

35. Apvrille, A. "U.S. Patent Application No. 10/178,130”., 2018 [Online] Available

at https://patentimages.storage.googleapis.com/36/dc/ba/6b59b f39b80c55/US20180077200A1.pdf Accessed on : 25th May, 2019

36. Zhu, W., Owen, C. B., Li, H., \& Lee, J. H. "Personalized in-store e-commerce with the promopad: an augmented reality shopping assistant." (2004). Electronic Journal for E-commerce Tools and Applications, 1(3).

37. Kameda, Y., Takemasa, T., \& Ohta, Y. "Outdoor see-through vision utilizing surveillance cameras" (2004, November). In Proceedings of the 3rd IEEE/ACM International Symposium on Mixed and Augmented Reality pp. 151-160). Available at doi>10.1109/ISMAR.2004.45 accessed on : 21st May,2019

38. Curtin, G. "6 ways augmented reality can help governments see more clearly", 13th Feb, 2017. [Online]World Economic Forum. Available at https://www.weforum.org/agenda/2017/02/augmented-realit y-smart-government/ accessed on : 20th May,2019

39. Damiani, L., Demartini, M., Guizzi, G., Revetria, R., and Tonelli, F., "Augmented and virtual reality application in industrial system: A quantitative review towards the industry 4.0.”, IFAC PapersOnLine 51-11 (2018) 624-630, 2018

40. Segovia, D., Mendoza, M., Mendoza, E., and Gonzalez, E., "Augmented Reality as a Tool for Production and Quality Monitoring” (2015). [online] Procedia Computer Science. Volume 75, Pages Available at 291-300. https://doi.org/10.1016/j.procs.2015.12.250 Accessed on : 5th May,2019

41. Bulearca, M., \& Tamarjan, D. "Augmented reality: A sustainable marketing tool" Global business and management research: An international journal, 2(2), 237-252., (2010). 